\title{
e-Health in Developing Countries: Bangladeshi Perspective
}

\author{
Suborna Afrin, Mohammad Arifuzzaman
}

\begin{abstract}
Currently, utilizing of Information and Communication technology (ICT) in medical sector has been gained a lot of interests in global community i,e. developed, developing and under developed countries. Now-a-days, ICT intervention in almost all arena of medical services is very evident in Bangladesh and stakeholders are getting its benefits with this IT-assisted medical services. As a matter of fact, the government of Bangladesh already has declared ICT as one of its priority sectors; hence a large amount of budget for enhancing ICT in medical sector have been allocated. This paper explains the present scenario of the use of IT in medical sector of Bangladesh as well as this is an initiative to provide some guidelines and recommendation for possible socio - economic improvement of Bangladesh through exploiting the potential of IT in health sector. In addition to that, this work also gives a brief summery and comparative study about the scenario of health services in developed and developing countries. Finally, this research tries to comprehensively focus on ICT potentials in medical area in order to find future visionary direction for the ICT based medical services that match the socio-economic constraint of the people at Bangladesh.
\end{abstract}

Keywords: e- health, m-health, EHR (Electronic Health Record), EMR (Electronic Medical Record), telehealth

\section{INTRODUCTION}

Todays, e- Health technology is highly demanded for the end users throughout the world, due to its advantages such as increasing awareness about health issues, creating and securing e-record. It should be noted that by developing of information and communication technology (ICT), our daily life is subjected to remarkable changes in all affiliate including health sector. In the literature, it is shown that many developed countries are already tremendously getting benefit from the e-health system. This system can be implemented in those countries which are developing, like Bangladesh, to increase both quality and quantity of community life. Thus, the Bangladeshi government emphasizes the e-health system for providing excellent healthcare facilities. The public hospitals in Bangladesh offer medical services to people at the community level which are completely free. According to the latest released reports by the government of Bangladesh,

Revised Manuscript Received on February 04, 2020.

* Correspondence Author

Suborna Afrin*, Department of ECE, East West University, Dhaka, Bangladesh

Dr. Mohammad Arifuzzaman, Department of ECE, East West University, Dhaka, Bangladesh

(C) The Authors. Published by Blue Eyes Intelligence Engineering and Sciences Publication (BEIESP). This is an open access article under the CC BY-NC-ND license (http://creativecommons.org/licenses/by-nc-nd/4.0/) there are 678 public hospitals, 482 upazila and union levels hospitals and 196 secondary \& tertiary levels hospitals, approximately. In addition, Bangladeshi people have access to 2,983 private hospitals and 5,220 private diagnostic centers [1-4]. The government hospitals have 18340 beds for the patients and it apparently is not enough for our huge population. Therefore, it is a great challenge for our government to provide high quality health care facilities. In the last few years, the government of Bangladesh has been commenced to promote the e-health system in the entire country for providing comprehensive health care services. The e-health system is included into the Digital Bangladesh campaign of government of Bangladesh. Various steps have been taken by the Ministry of Health \& Family Welfare to develop the e-Health services. In this regard, a Management Information System (MIS) department which is under Directorate General of Health Services (DGHS) has been established. For improving the quality, efficiency and safety of the e-Health system, an extensive collaboration between multiple sectors, such as private organizations, NGOs, etc., has been made [2-4]. New capabilities delivery in healthcare is the main focus in healthcare and for hospitals and healthcare providers. It is based according to the national ICT policy of Bangladesh (2002) [5].

In [4], the authors have discussed about e- health and its Current Status, Challenges as well as some Future Direction. The authors in [6], have described about integrating data into electronic health record and challenges for quality improvement of electronic health record in developing countries. In [7], there has been given a lot of information about opportunities and challenges of e- health and m-health services in Bangladesh. In [8], the authors give a description about the factors which are influencing elderly people in Bangladesh for accepting m-health. Similar works have been done in [9-12], the authors have discussed about the acceptance of $\mathrm{m}$ - health of patients and physicians and also present states and opportunity of telemedicine.

This paper has been organized as follows. Section 2 discusses about the current scenario of e-health record management in Bangladesh, a comparison between e-health system in the developed countries and developing countries is provided in Section 3. Section 4 discusses the details of the dimensions of e-health and possibilities in Bangladeshi perspective. Discussion and the future direction with specific recommendations will be proved in Section 5. Finally, Section 6 concludes the paper.

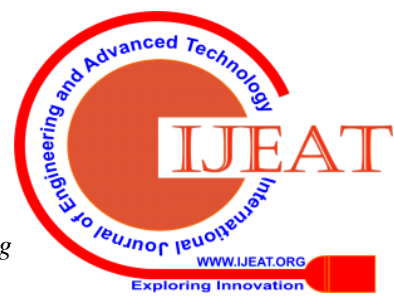




\section{Present scenario of health record management in Bangladesh}

e-health: e-health is a concept which is a combination of medical informatics, public health and business using information and communications technologies in healthcare. The term e-health characterizes a technical development as well as a mind's state. It is a way of improving healthcare. It has some attributes which include a networked commitment, global thinking. By using information and communication technology, it has thinking of locally, regionally, and worldwide. It has secure use of information and communication technologies. By using this technology, citizens are getting the cost-effective health services. [WHO and DGHS]

First it is used in 1997. e-health system is used for improving patient care, safety of all records. At the point of care, for patients the information it provides accurate, complete and up to date. It minimizes the costs for providing improved safety, reduction of paperwork, reduction of duplication of testing, and for providing improved health.

e-Health has some Sub-domains which include Electronic Health Records (EHR), Electronic Medical Records (EMR), Telehealth and telemedicine, Health IT systems Consumer health IT data, Mobile Health (mHealth) [1].

A few years ago, hospitals used to maintain their record in paper-based way. But now-a- days with the development of IT sector in Bangladesh the paper based system is reduced. Now some big private hospitals are preserving the records of their patients through electronic medical record (EMR) system. But still maximum private and public hospitals do not believe in preserving their health record in electronic medical record system. They still believe on paper based system. The probable reasons of using the paper based are so many. Maximum hospitals are not interested in buying computer. They think it is wastage of money for reserving data. There is lacking of efficient people for data management. Patients are also not aware of preserving their medical record in a digital way. All these factors are still responsible for not complete digitalization in medical record management [14].

\section{COMPARISON BETWEEN DEVELOPED AND DEVELOPING COUNTRIES}

The countries which are developed and developing have accepted different effective challenges for improving the health service in their perspective. Though there are a lot of dimensions from which this section can be elaborated, since the focus of the paper is more on e-health systems of Bangladesh, we discuss very few areas of e-health services in this section.

\section{A. Developing Country}

In Bangladesh, a few software companies and mobile operators (Grameenphone, Robi, Banglalink etc) have been just started to provide medical information with secure access. Among them the largest telco operator "Grameenphone" have HealthLine Service, medical information services and so on EMR system has just collected more information such as data entry, data collection, image processing (laboratory test) and so on with secure access. [15]. Since there is no health insurance card for the people of Bangladesh, they cannot use their EMR in their emergency time. Financial accessibility must be kept in EMR system so that every kind of people can use it with their reasonable money. Availability can be used according to opportunity to access health service when people can be needed in any time [16]. Most of the cases specially people who are not privileged in using modern technologies do not know how to create or sign up an account to use medical software as most of the people are living below the poverty line and still not uneducated. Educated people must provide training facilities to under-privileged people about peer-to peer learning and social networking services.

\section{B. Developed Countries}

Every health ministry of the world which countries are developed is mandatory to open a medical insurance for every classes of people such as Canada, USA, Germany, Japan, Singapore. These countries associated with both the most expensive system (USA) and the least expensive system (Singapore), single payer as well as universal multiple payer, government sponsored and employer sponsored insurance [17].

The overview of health some facilities for several developed and developing countries are summarized in Table 1 and Table 2.

Table I: e-health record system in different developed countries

\begin{tabular}{|l|l|l|l|l|}
\hline Country & Simple Characterization & Primary Sponsor & Number of plans & Mandatory \\
\hline Canada & Single payer & Government & 1 & Yes \\
\hline USA & Employed sponsor insurance & Employers & $>1200$ & No \\
\hline Germany & Universal multi-payer & Government & 200 & Yes \\
\hline Japan & Employed sponsored insurance & Employers & $>3000$ & Yes \\
\hline Singapore & Subsidized self-insurance & Self & 0 & Yes \\
\hline
\end{tabular}


Table II: Comparison between developed and developing countries

\begin{tabular}{|c|c|c|}
\hline Characteristics & $\begin{array}{l}\text { Developed } \\
\text { countries }\end{array}$ & $\begin{array}{l}\text { Developing } \\
\text { countries }\end{array}$ \\
\hline Medical Record & Developed & Partial \\
\hline Health insurance & mandatory & Optional \\
\hline Medical cost & High & Low \\
\hline $\begin{array}{ll}\text { Specialist } & \text { doctor } \\
\text { visit delay } & \end{array}$ & $\begin{array}{l}\text { Very fast to } \\
\text { get treatment }\end{array}$ & $\begin{array}{l}\text { Difficult to get } \\
\text { an } \\
\text { appointment }\end{array}$ \\
\hline $\begin{array}{l}\text { Quantity of } \\
\text { e-health tools use } \\
\text { in hospitals }\end{array}$ & mandatory & Several \\
\hline $\begin{array}{l}\text { Quantity of } \\
\text { e-health tools used } \\
\text { by doctors }\end{array}$ & mandatory & A few \\
\hline $\begin{array}{l}\text { Wire able device } \\
\text { monitoring }\end{array}$ & $\begin{array}{l}\text { Completely } \\
\text { Under } \\
\text { observation }\end{array}$ & Partial \\
\hline Vaccination record & Developed & Partial \\
\hline $\begin{array}{l}\text { Operator for } \\
\text { e-health tools use }\end{array}$ & Efficient & $\begin{array}{l}\text { lack of } \\
\text { efficient } \\
\text { people }\end{array}$ \\
\hline
\end{tabular}

\section{E-HEALTH: DIFFERNENT DIMENSIONS AND POSSIBILITIES IN BANGLADESH PERSPECTIVE}

\section{A.Electronic Health Record (EHR)}

It is an electronic version of patient medical records. It is also maintained time to time. All the necessary clinical information of patient is maintained very carefully. It includes statistics, notes of improvement, critical health issues, and list of used drugs in treatment of the specific patient, major health issue, previous medical record, cure probability and all tests reports [18]. By Using EHR we are getting lots of benefits. It reduces the happening medical error. It reduces the repeat of same test and providing faster treatment. It helps patients to take better decisions as all information are well informed before. It makes the health information available which has improved the perfection and transparency of all medical records. It also enhances privacy and security of patient data.

Launching EHR in Bangladesh: In November 2015, Electronic health record was successfully put in the motion which was launched as experiment at Kaliganj sub-district and in Gazipur district in March 2016. To identify environmental and system challenges are the main goal of this experiment. Currently sub-district and district hospitals are using Bahmni [19] technology as the clinical system. Bahmni is a thought Works-developed distribution of Open
MRS. EHR is also used as a cloud-hosted CHW application at community clinics [19].

Some private hospitals and clinics are using this EHR method. Now -a -days some private and public hospitals are trying to adopt this method. The Ministry of Health \& Family Welfare has an ongoing project which has a goal to evaluate and develop a plan for accepting EHR in Bangladesh. This project includes to use of EHR systems hospitals in Bangladesh.

There are some difficulties which are involved in using EHR systems in public hospitals of Bangladesh. There is a huge patient load but shortage of human resources and ICT resources. These are technical problems. On the other hand, some people do not consider the system helpful. People living in rural area do not have any knowledge and trust about using technical ways. Along with these problems, hospitals also not interested about adopting this method because it will need human and ICT equipment. They think that it will increase their maintenance cost.

\section{B. Electronic Medical Records (EMR)}

Electronic medical record (EMR) is a paper chart which is a version of digital form having all of a patient's medical history. It is mostly used by providers for diagnosis and treatment. An EHR is more details form of report of the patient health status while an EMR is a brief of a patient's medical history. [20]

There are some benefits of using Electronic Medical Records. It is efficient in tracking data by time. It has efficiency in identifying patients for preventive visits and screenings. It can monitor to measure some certain parameters. The patients who come for vaccinations and checking blood pressure are monitored by this system. Practically overall quality of health care is improved. [21]

A few private hospitals in Bangladesh are using EMR system. But the list is very short. Scarcity of ICT equipment, maximum hospitals are not using it. The situation is improving gradually.

\section{C.Telehealth and Telemedicine}

Telehealth is a method for providing care of health, public health, and education about health and support for providing health care by using telecommunications technologies. Telehealth encircles a variety of technologies for providing virtual medical, health, and education services [22].

The combination of telecommunication and information technology is used for giving service of clinical health care system from a certain range in telemedicine system. In overcoming discrepancy barriers it is used. In distant rural communities where, medical services are consistently not available is accessible by telemedicine services [22]. There are several befits of using telemedicine. Telemedicine helps patient to get access to healthcare faster. It can evaluate diagnose and treat patients remotely.

There are also some befits of Telehealth. With the help of remote consultations and monitoring, admissions and readmissions are reduced which were necessary before. It helps patients to manage health conditions more effectively at home. Patients can have benefit from having the staff easily who are already using this system.

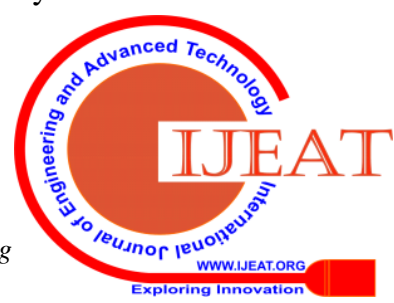


They easily can have any medical records from specialists. This system has already improved the level of care. Any important information can be accessed quickly and efficiently still a patient is at home. More advanced solutions are offered by this system. It is making in a better light. Without the components of Telehealth, the community view to the people would not be possible. Physicians can provide their expertise suggestion who are in remote area. It would not possible to provide such health care service without Telehealth. Physicians need not to travel in order to see patients in the remote areas which is saving their time and money [23].

In Bangladesh, a charitable trust, Swifne Charitable established first telemedicine link in 1999. It the link was established between the Centre for the Rehabilitation of the Paralysed (CRP) in Dhaka (the capital of Bangladesh) and Royal Navy Hospital, Haslar, UK . This project was email based. The Bangladesh project was successful. As a result, digital cameras and tripods were supplied to more hospitals in other developing countries by the swinfen charitable trust.

In mid - 2000: Rural tele-health initiatives were taken using wireless technology by Grameen Communications. A unique telemedicine Service "Health Line Dial 789" has started by Telemedicine Reference centre Ltd. And Grameen phone in November, 2006. Grameen phone which is GSM infrastructure based call centre have 10 million subscribers. These call center are providing different types of medical information facility such as emergency service (SMS based LAB report, ambulance) and real time medical consultation over mobile phone. [24]

Telenor Health launched via Grameenphone an initiative named Tonic. This service provides lots of health related services such as health and illness information, suggestions for positive health change and editorial style content. It has 24-7 helpline for GP users in which it charges BDT 5 per minute, for giving a basic diagnosis by doctors. A discount service is also offered for its members in selected hospitals in Dhaka by the startup. [25]

Lots of people are using tele- health services. But still, a large portion of Bangladesh is not using tele- health service because of lack of knowledge. Recently, some online website are launched for patients of Bangladesh. The names of some very well-known website names are Doctorola.com, Doctorsbd.com, E-medical point.

Doctorola.com is such a website which is used for finding the required doctor, hospital or blood donor easily with a less effort. This website helps out patient in appointment process of the doctor or contacts the blood donor quickly with almost a single click. It has 8069 verified doctors who have specializations on different categories. It covered already 62 districts [26]. Doctorsbd.com is also a very useful website for patients. It helps out patients in searching doctors in their required locations. E-medical point is constantly trying to publish accurate and update Bangladeshi doctor's information but the doctors list is not accurate or complete. They are trying to improve the online doctors list of Bangladesh [27].

\section{D.Mobile Health Technology or mHealth}

mHealth (mobile health) is a term which is used in medical care by using mobile phones and other wireless technology. There are some basic differences between mHealth and telehealth. Telehealth is about providing healthcare by using latest technology. On the other hand, patient can take care oneself by using mobile in mhealth. Consumers can capture their own health data in smart phone and tablet apps. [28]

Patient can get access clinical information by using mobile apps. Patient can have communication with patients through patient portals. It offers monitoring of patients which is real-time and provides health care in remote. [29] These are the benefits of mobile health or mHealth. By using mobile apps user can get important information about cardio logical diseases, diabetes, obesity, chronic diseases, and smoking cessation. These mobile apps are used to monitor, to prevent, and to detect diseases. It is also used for providing more advanced services like present basic diagnosis. There are a huge number of mobile apps in Google play store such as Calorie Counter and Diet Tracker, Daily Carb Carbohydrate, Glucose, Medication, Blood Pressure and Exercise Tracker, Noteness, Office-Fit ete. [30] Calorie Counter and Diet Tracker is used for Diet application for counting calories, food tracking, exercise, and weight goals. Furthermore, it explores social aspects including links to friends as a motivation feature. Daily Carb - Carbohydrate, Glucose, Medication, Blood Pressure and Exercise Tracker is an application that tracks daily nutrition intake of food, crabs, fiber, fat, tracks quantity of water intake, readings of glucose, HbA1c, blood pressure, heart rate, weight, exercise, medications, and insulin. Noteness is multiple sclerosis diary application that allows a user to track and monitor injections and symptoms. Office-Fit is an application that contains and offers several exercises against work-related pains and stress. A very few people are using this system but maximum people are not using it. As Bangladesh is a developing country, many people of Bangladesh still living below the poverty line. Good number of the people are not using smart phones and tabs. The people who are using smart phones and tabs also not using m-health because they don't have proper knowledge of m-health .

\section{E. Clinical Health IT Systems}

Clinical health IT systems are various types. They are radiology, nursing health IT systems, computer-assisted diagnostics, medical imaging, and surgery training and planning systems. The benefit of clinical Health IT system is which help physicians to provide more accurate diagnoses and treatments. Bangladeshi Hospitals are gradually adopting these.

\section{F. Consumer health informatics}

Now-a-days eHealth informatics is one of the most popular technologies in global world especially in developed countries. Many people are enjoying the effectiveness of improving the improvement of medical sector by using information technology in healthcare (health IT) and eHealth solutions are the blessing to people [31]. Though the growing interest in this field is referred to as consumer health informatics (CHI), the CHI applications review is not continuous [32]. Consumer Health Informatics (CHI) is the communication source between patient and doctor about patient's health condition. It is a bridge between the patients and health resources as it is the sub-branch of health informatics [33]. 
The American Medical Informatics Association has given a definition as "the field devoted to informatics from multiple consumer or patient views"[34].There are various types of Health Informatics. They are medical informatics, nursing informatics, dental informatics and public health informatics. Medical informatics two types such as Clinical informatics and Bioinformatics. On this paper from all informatics, we will discuss only public health informatics.

It is used for analyzing, formalizing, and modeling consumer preferences and information needs. It is giving security to their every patient with their own page and have access to their own page from where they can their drugs list, tests results and so on. If people use the e-Health Informatics system, most of the cases money will be saved. [38].

After independence in 1971, in Bangladesh, people have been suffered various types of disease due to unconscious about their health. In public and private sector, they didn't get their proper treatment. Now-a-days; Bangladeshi people thought that they will have launched e-health Medical System like developed countries. In Bangladesh, health care technology has faced a very big problem with a huge amount of data. They have no infrastructure, no medical management system and so on. These systems are unstructured, unorganized and unauthorized. Bangladesh has achieved some attractive developments in population health status is present by achieving Millennium Development Goals (MDG 4) in Bangladesh by reducing the death of child before the 2015 target. Other key indicators including maternal death, immunization coverage, and survival from some infectious various diseases including malaria, tuberculosis, diarrhea etc are improving rapidly [35].

Though Bangladesh is a developing country but e-Health Informatics is a very big challenges issue according to Bangladeshi perspective. However, few challenges issue for health service is remaining critical. According to World Health Organization (WHO), the Gross Domestic Product(GDP) spending amount on health services is $3 \%$ [36].However, government spent on health is only $34 \%$ of the Total Health Expenditure(THE),the rest(66\%) being out-of-pocket(OOP) expenses[37]. Bangladesh has improved in health service related Millennium Development Goals(MDGs) especially MDG4 and MDG5.

\section{FUTURE DIRECTIONS AND RECOMMENDATIONS}

\section{Knowledge Base}

A good website can serve as a hub which will contain all medical related information. The website will hold names, specializations and contact details of all Bangladeshi doctors such as doctorola.com, Doctorbd.com, Healthprior21.com, Rx71. In October 2015, Doctorola has been launched officially. A huge numbers of doctors (near to five thousands) and hospitals (three hundred) has already been working with the company [up to December 2015] [39]. People are getting appointments of doctors through online. There is a website which have live chat option, mobile apps. To manage appointments and everything there is a call center. Appointment management is handled for a few hospitals in Dhaka by the startup. Doctorbd is largely a doctors' directory and appointment management system which is Started in 2004. It has database which have database of blood donor, information of hospital, information of medical institute, info of diagnostic center, clinics and kidney/eye bank.
Appointments can be taken through online by Patient to their desired doctors. The online consultation is a great option where problems can be submitted by the patient to the chosen doctor and help is got within 24 hours. One of the earliest initiatives in the digital health space is Health prior. Health news and information is offered by the platform. Free medical books and videos can be gotten from e-library which is a part of e-appointment. E-appoinment also has an e-store. Doctors and hospitals directory can be provided by a site named Rx71 by which patients can find doctors and hospitals. Appointment can also be made by it. A huge health related content in Bangla is building up by it. It has a vision to help people in living a healthy life by creating health awareness. It is also educating people on health issues. A mobile app has also launched recently by the startup. [40]It will help patient to find and reach their required doctor. It will also carry contact details of ambulance services and emergency medical equipment. There will also be contact details of all medical stores who can provide medicine in home delivery services. It will also contain the links of medical related apps. With the digitalization of Bangladesh, the number of smart phone user's increases and people are using various medical related mobile apps. So in the website there will be the numbers and rates in terms of using different apps.

\section{Social networking}

Now a day's people are using social Medias very usually. Social Medias can be used for medical awareness work. If there will be a social page or website where all patients of same disease share their survival experience then other patient will get inspiration for survive in case of severe diseases like Hepatitis A, Hepatitis E, Malaria, swine flu (H1N1), tuberculosis (TB), hepatitis B, cholera, meningitis, Ebola virus diseases, food-borne gastroenteritis, salmonellosis, and various types of cancer. There are some pages in social networking site and some websites. In those sites have a definition and the causes, symptoms and treatments of common diseases. There are information about various genetic diseases as well as infectious. There are full information of communicable diseases such as autism, strokes, skin conditions, eye disease, diabetes, cancer, heart disease.[41,42]When a patient suffers one disease, s/he has the exact information about that. The person who came back from the severe disease, his/her survival experience can motivate other patient for survival. As people of Bangladesh are being literate day by day, with the increasing literacy rate awareness in people are also increasing. People are more conscious about their health issue. [43]

In Bangladesh medical system is not sufficient for all over population. In case of some diseases we do not have the specialized hospital and privileges. So the all patients can raise their voice for hospital and other issues and they can make a group in social media for getting their wants. The patient can do pray to government for their wants. 


\section{Remote support for telehealth and telemedicine}

Bangladesh Telecommunication Regulatory commission (BTRC) has published a report in which the total number of Mobile Phone subscriptions has reached 128.281 million till January 2017, and the total number of Internet Subscribers has reached 67.245 million till February, 2017. [44, 45] Thus, it is evident that uses of smart phone and internet is highly flexible in the context of Bangladesh.

Table III: Increasing rate of mobile user in Bangladesh

\begin{tabular}{|l|l|}
\hline Year & $\begin{array}{l}\text { Mobile phone using } \\
\text { rate in million }\end{array}$ \\
\hline 2017 & 141.679 \\
\hline 2016 & 126.391 \\
\hline 2015 & 133.72 \\
\hline 2014 & 120.35 \\
\hline 2013 & 113.784 \\
\hline 2012 & 97.18 \\
\hline
\end{tabular}

Increasing Rate of mobile user from year of 2012 to 2017 Therefore, touch screens and other technologies seem to be an acceptable idea. Rural population (\% of total population) in Bangladesh was reported at $64.96 \%$ in 2016, according to the World Bank collection of development indicators, compiled from officially recognized sources. [46] As we still do not have sufficient hospitals, telehealth and telemedicine are the solution of it. In our country a group of people think in the case of any silly diseases like normal virus fiver and flue they need consultations $\mathrm{f}$ specialized doctors. As a result, it is making a worse situation as we have not sufficient specialized doctors. The patients who need the specialized doctors really, they are not getting proper treatment. For this case telehealth and telemedicine can be the best solution. We have some MBBS doctors who can give easily treatment in case of sufferings of common diseases.

\section{e-health research}

Every country has unique Geographic structure, culture and social views because of all uniqueness problems are unique. So we could not implement others countries research and problem solving strategies for our country. Our solutions should cover end user satisfactory level. Then we will retrieve maximum outcome.

\section{CONCLUSION}

Developed countries have already been embraced by the significant advancements of the applications of e-health in the health care sector. By using the ICT in different ways, developing countries are also combating to readjust the health care sector. Both government and private sector are trying to improve the health sector by using ICT in Bangladesh in spite of a lot of obstacle. From the above discussion it is clear that, the present situation of e-health is better than before but not at matured stage. It is expected that with the implementation of ICT in health sector will bring a very positive change for Bangladesh.

\section{REFERENCES}

1. http://cpd.org.bd/wp-content/uploads/2017/06/Presentation-on-An-Ana lysis-of-theNational-Budget-for-FY2017-18.pdf

2. http://www.dghs.gov.bd/licts_file/images/Health_Bulletin/HB2012_C H/HB2012_CH5_Senondary-tertiary-HCare.pdf

3. http://app.dghs.gov.bd/localhealthBulletin2016/publish/publish.php?or $\mathrm{g}=10000033 \&$ year $=2016 \& \mathrm{lvl}=5$
4. Hoque, Md Rakibul, Md Fahami Ahsan Mazmum, and Yukun Bao. "e-Health in Bangladesh: current status, challenges, and future direction." The International Technology Management Review 4, no. 2 (2014): 87-96.

5. http://liu.diva-portal.org/smash/get/diva2:581963/FULLTEXT01.pdf

6. Blaya, Joaquin A., Hamish SF Fraser, and Brian Holt. "E-health technologies show promise in developing countries." Health Affairs 29, no. 2 (2010): 244-251.

7. Ahmed, T., Bloom, G., Iqbal, M., Lucas, H., Rasheed, S., Waldman, L., Khan, A.S., Islam, R. and Bhuiya, A., 2014. E-health and M-Health in Bangladesh: Opportunities and Challenges (No. IDS Evidence Report; 60). IDS.

8. Hoque, Md, and Golam Sorwar. "Factors Influencing mHealth Acceptance among Elderly People in Bangladesh." arXiv preprint arXiv:1606.00874 (2016).

9. Ashraf, Sania, Carolyn Moore, Vaibhav Gupta, Anir Chowdhury, Abul K. Azad, Neelu Singh, David Hagan, and Alain B. Labrique. "Overview of a multi-stakeholder dialogue around Shared Services for Health: the Digital Health Opportunity in Bangladesh." Health Research policy and systems 13, no. 1 (2015): 74.

10. Hoque, M. Rakibul, Yukun Bao, and Golam Sorwar. "Investigating factors influencing the adoption of e-Health in developing countries: A patient's perspective." Informatics for Health and Social Care 42, no. 1 (2017): 1-17.

11. Hoque, Md Rakibul, Adnan Albar, and Jahangir Alam. "Factors influencing physicians' acceptance of e-health in developing country: An empirical study." International Journal of Healthcare Information Systems and Informatics (IJHISI) 11, no. 1 (2016): 58-70.

12. Prodhan, Uzzal Kumar, Mohammad Zahidur Rahman, and Israt Jahan. "A survey on the assessment of the present states and opportunities of telemedicine in Bangladesh." International Journal of Computer Science and Information Security 15, no. 1 (2017): 1.

13. https://innovatemedtec.com/digital-health/ehealth

14. Hillestad, Richard, James Bigelow, Anthony Bower, Federico Girosi, Robin Meili, Richard Scoville, and Roger Taylor. "Can electronic medical record systems transform health care? Potential health benefits, savings, and costs." Health affairs 24, no. 5 (2005): 1103-1117.

15. https://arxiv.org/ftp/arxiv/papers/1507/1507.03659.pdf[6]

16. http://onlinelibrary.wiley.com/doi/10.1196/annals.1425.011/pdf[7]

17. Jha, Ashish K., Catherine M. DesRoches, Eric G. Campbell, Karen Donelan, Sowmya R. Rao, Timothy G. Ferris, Alexandra Shields, Sara Rosenbaum, and David Blumenthal. "Use of electronic health records in US hospitals." New England Journal of Medicine 360, no. 16 (2009): 1628-1638.

18. Kalra, Dipak. "Electronic health record standards." Yearbook of medical informatics 15, no. 01 (2006): 136-144.

19. https://www.thoughtworks.com/clients/dghs-bangladesh

20. https://www.usfhealthonline.com/resources/key-concepts/ehr-vs-emr/

21. Barrows Jr, Randolph C., and Paul D. Clayton. "Privacy, confidentiality, and electronic medical records." Journal of the American medical informatics association 3, no. 2 (1996): 139-148.

22. Perednia, D.A. and Allen, A., 1995. Telemedicine technology and clinical applications. Jama, 273(6), pp.483-488.

23. Park, E.J., 2006. Telehealth technology in case/disease management. Professional Case Management, 11(3), pp.175-182.

24. Telemedicine Reference Centre Ltd. http://www.trclcare.com

25. https:/futurestartup.com/2016/10/25/digital-healthcare-startups-to-wat $\mathrm{ch} /$

26. https://doctorola.com/

27. http://www.emedicalpoint.com/index.php?page=doctor-search

28. https://www.google.com/search?q=difference+between+telehealth+and +mobile+health\&oq=difference+between+telehealth+and+mobile+heal th+\&aqs=chrome..69i57.23605j0j4\&sourceid=chrome\&ie=UTF-8

29. Kumar, Santosh, Wendy J. Nilsen, Amy Abernethy, Audie Atienza, Kevin Patrick, Misha Pavel, William T. Riley et al. "Mobile health technology evaluation: the mHealth evidence workshop." American journal of preventive medicine 45, no. 2 (2013): 228-236.

30. https://www.sciencedirect.com/science/article/pii/S1532046415001136

31. http://www.doctorsbd.com/

32. https://www.ahrq.gov/downloads/pub/evidence/pdf/chiapp/impactchia. pdf

33. Friede, Andrew, Henrik L. Blum, and Mike McDonald. "Public health informatics: how information-age technology can strengthen public health." Annual review of public health 16, no. 1 (1995): 239-252. 
34. Ahmed, Tanvir, Gerald Bloom, Mohammad Iqbal, Henry Lucas, Sabrina Rasheed, Linda Waldman, Azfar Sadun Khan, Rubana Islam, and Abbas Bhuiya. E-health and M-Health in Bangladesh: Opportunities and Challenges. No. IDS Evidence Report; 60. IDS, 2014.

35. http://www.wpro.who.int/asia_pacific_observatory/hits/series/bgd_heal th_system_review.pdf[copy

36. http://www.hsprj.com/health-maintanance/editorial-health-systems-inbangladesh.pdf

37. https://www.healthit.gov/providers-professionals/electronic-medical-re cords-emr

38. Tarassenko, Lionel, Clive Peggram, Paul Hayton, Oliver Gibson, Alastair George, and Jeremy Wheeler. "Telemedicine system." U.S. Patent Application 10/528,365, filed February 16, 2006.

39. http://www.hsprj.com/health-maintanance/editorial-health-systems-inbangladesh.pdf

40. Brooks, Rochelle, and Courtney Grotz. "Implementation of electronic medical records: How healthcare providers are managing the challenges of going digital." Journal of Business \& Economics Research (JBER) 8 , no. 6 (2010).

41. https://futurestartup.com/2016/10/25/digital-healthcare-startups-to-wat $\mathrm{ch} /$

42. https://www.livescience.com/36519-diseases-conditions-symptoms-tre atments.html

43. https://www.lonelyplanet.com/bangladesh/health

44. http://www.theglobaleconomy.com/Bangladesh/Literacy_rate/

45. http://www.btrc.gov.bd/content/mobile-phone-subscribers-bangladeshjanuary-2017

46. http://www.btrc.gov.bd/content/internet-subscribers-bangladesh-februa ry-2017

47. https://tradingeconomics.com/bangladesh/rural-population-percent-of-t otal-population-wb-data.html

\section{AUTHORS PROFILE}

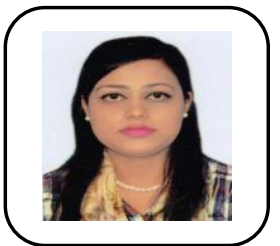

Suborna Afrin, completed the B.Sc. degree in Electronics and Telecommunications Engineering under ECE (Electronics and communications Engineering) department from East West University, Dhaka, Bangladesh in 2017. She is doing her Masters in Telecommunication in East West University.

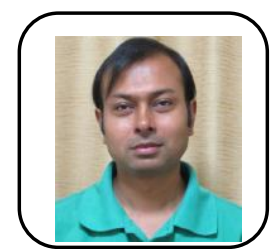

Dr. Mohammad Arifuzzaman, received the B.Sc degree in Computer Science \& Engineering from BUET (Bangladesh University of Engineering and Technology). He received Masters in Information and Telecommunication Studies, from Waseda University, Tokyo, Japan in 2012 and Ph.D in Information and Telecommunication from the Waseda University, Tokyo, Japan in 2015. He worked as a postdoctoral fellow at Memorial University of Newfoundland, Canada. His research interest is in AI and Data Science, Future Internet Architecture, Green Wireless and Sensor Communication.

Currently, he is an Assistant professor at Department of ECE, East West University, Dhaka, Bangladesh. Before that, he worked as a faculty member of IICT, BUET. Dr. Arif published 60+ research papers in International Journals (including IEEE Sensors Journal, IEEE Access Journal, IEEE Transactions on Instrumentation \& Measurement, Orphanet journal of rare diseases etc) and conferences (including IEEE Globecom, ITU Kaleidoscope etc). He achieved best paper award at ITU Kaleidoscope Conference, Cape Town, South Africa, 12-14 December 2011. Dr. Arif worked as a reviewer of different peer reviewed journals including IEEE Sensors Journal, IEEE Communications Letters, IEEE Communications Surveys \& Tutorials, Computer Networks Journal - Elsevier, IEEE Internet of Things (IoT) Journal etc. 